\title{
CONTROL UNIT FOR SEAT WITH VARIABLE STIFFNESS
}

\author{
Radek Votrubec, David Cirkl \& Michal Sivcak
}
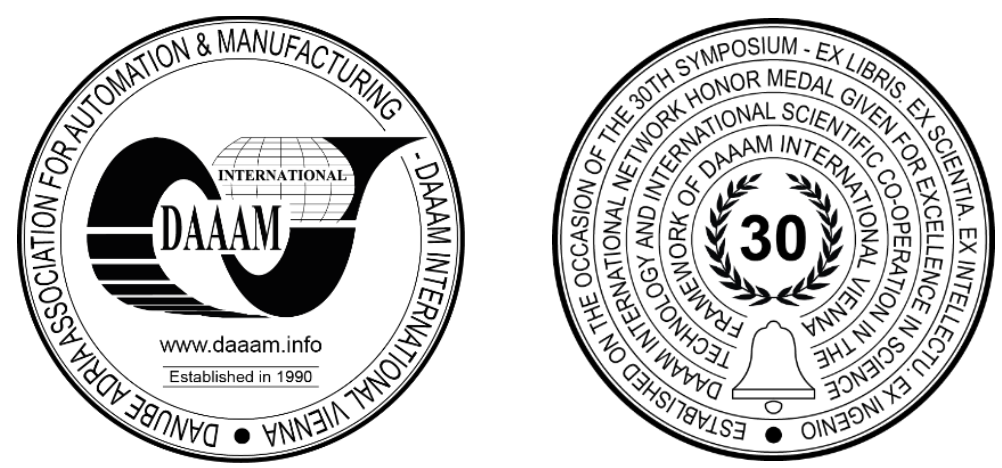

This Publication has to be referred as: Votrubec, R[adek]; Cirkl, D[avid] \& Sivcak, M[ichal] (2021). Control Unit for Seat with Variable Stiffness, Proceedings of the 32nd DAAAM International Symposium, pp.0058-0066, B. Katalinic (Ed.), Published by DAAAM International, ISBN 978-3-902734-33-4, ISSN 1726-9679, Vienna, Austria

DOI: $10.2507 / 32$ nd.daaam.proceedings.009

\section{Abstract}

This paper describes the control system of car seat with variable stiffness. The pressure in pneumatic element inside the seat is controlled. It improves the comfort of sitting person and it has an influence against the fatigue. The control system is based on microprocessor using the Arduino board. There are several control strategies using two-state and proportional pneumatic valves. Central system with air reservoir or own compressor is used.

Keywords: Vibroisolation; Car Seat; Arduino; Pneumatic System; Active Damping.

\section{Introduction}

At our Technical University in Liberec, we have been dealing with vibration isolation systems for many years [2], [7]. This issue is very current [3], [4], [5], [7] We are now developing seats with variable seat stiffness, Fig.1. One or more pneumatic elements are inserted into the seat cushion.

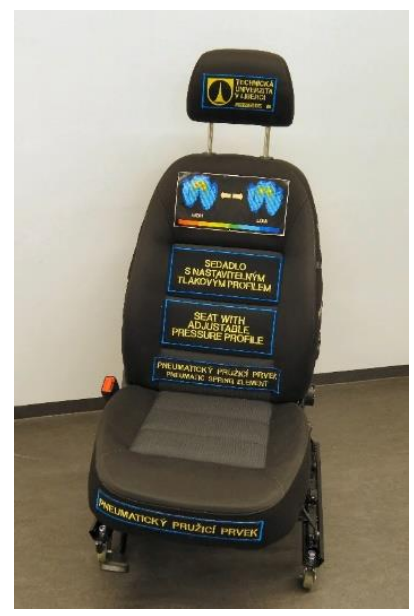

Fig. 1. The seat with variable stiffness 
The control of the pressure in the pneumatic element affects the stiffness of the seat. At zero pressure, the support is provided by a foam filling [1], [6]. The seat with variable stiffness brings several benefits. Adjusting a softer or harder seat improves the driver's driving comfort. Dynamic changes in stiffness contribute to reducing the feeling of fatigue.

The use of seats with variable stiffness is expected in the areas of cars and trucks, work machines and means of transport, both at the driver's seat and for passengers. Evaluating of comfort is difficult. Parameters such as pressure or temperature measured in the contact zone between the seat and the body can be used to objectively assess the improvement, fig. 2 .
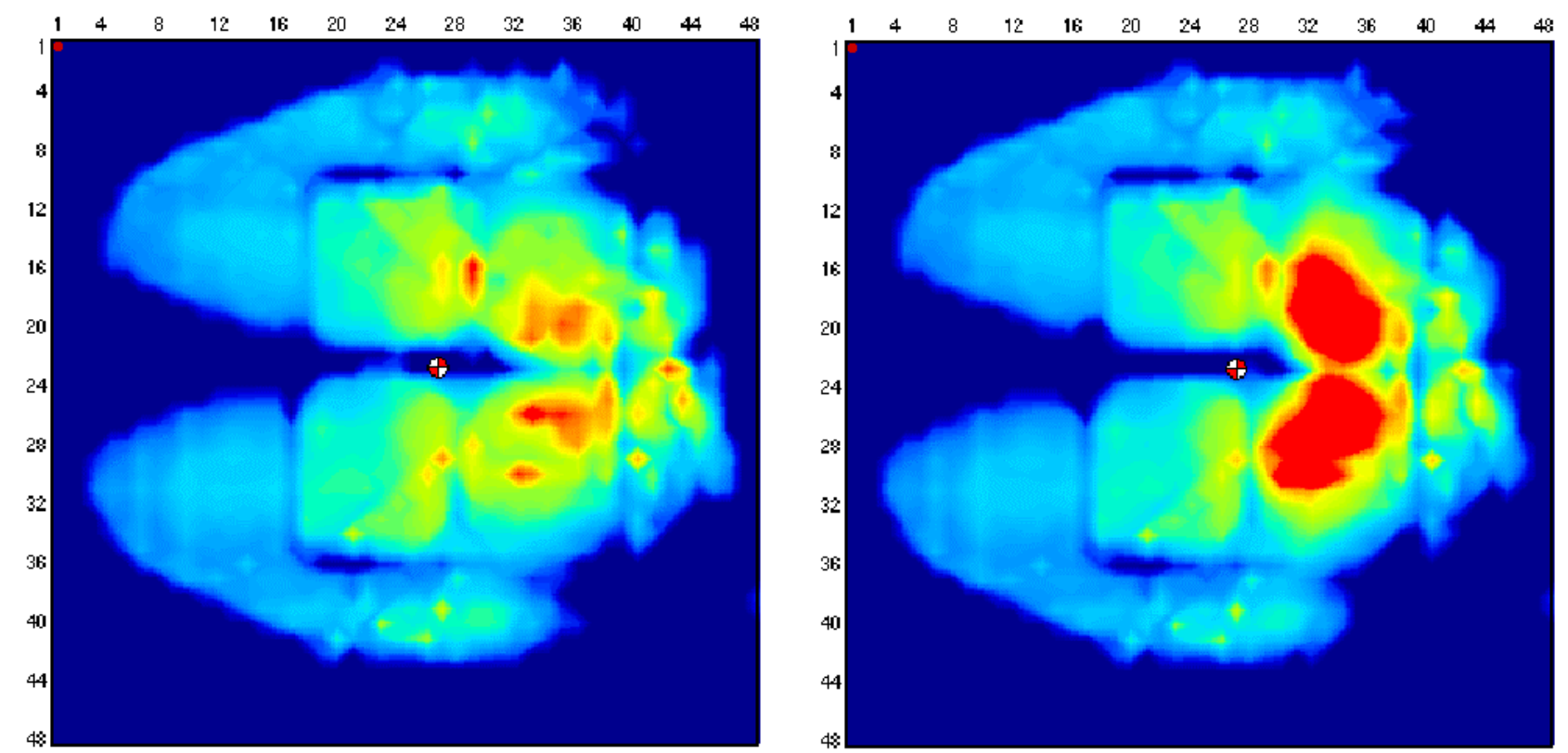

Pressure (1-21kPa)

Fig. 2. Pressure measurement in contact zone between the seat and body.

As part of the solution of this project, a requirement arose to create a control unit for this seat with adjustable stiffness. In previous years, the seat was controlled using a measuring card and a control computer with Labview. This variant is only suitable for development purposes. The project has now moved towards commercial use and it was necessary to replace this solution with a separate microprocessor-based control unit. Similar control units have been developed in the past [8], [9]. This task was further divided into two variants.

The first version of the control unit is used for laboratory use. It enables the operation of the seat in all control modes using various types of sensors, valves, etc. It has the possibility of setting a large number of parameters and it is possible to perform laboratory measurements on it, export the measured data for further processing. The second version consists of only the most necessary components and switches only between the two driving modes. It is optimized in terms of size, price, reliability, heat dissipation and electromagnetic compatibility.

\section{Variants of the source of compressed air}

The pneumatic circuit consists of a compressor C, pneumatic valves Vin, Vout, pressure sensors PS, PR and a pneumatic element of the seat $\mathrm{S}$. Depending on the source of compressed air used, the solution can be divided into three variants. The simplest version is shown in Fig. 3. The source of compressed air here is only a controlled compressor. The compressor can be controlled either two-state, on-off, or continuously using pulse width modulation.

For this connection, it is necessary to use a compressor that seals and maintains pressure when switched off. Or it is possible to connect a non-return valve behind it. Schematically, the control circuit is indicated in blue with the control unit R. In this case, the compressor $\mathrm{C}$ and the outlet valve Vout are controlled on the basis of the pressure measured by the sensor PS. 


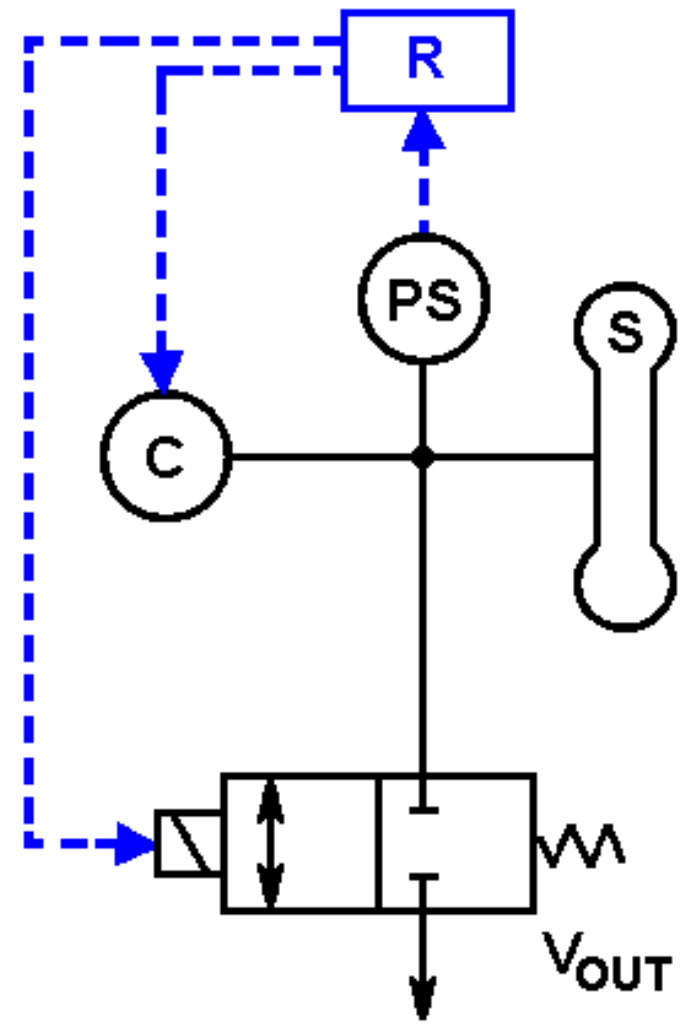

Fig. 3. Pneumatic circuit with own local compressor only

The second variant is shown in Fig.4, where an inlet valve is connected in series to the compressor. The control of this valve is synchronized with the control of the compressor.

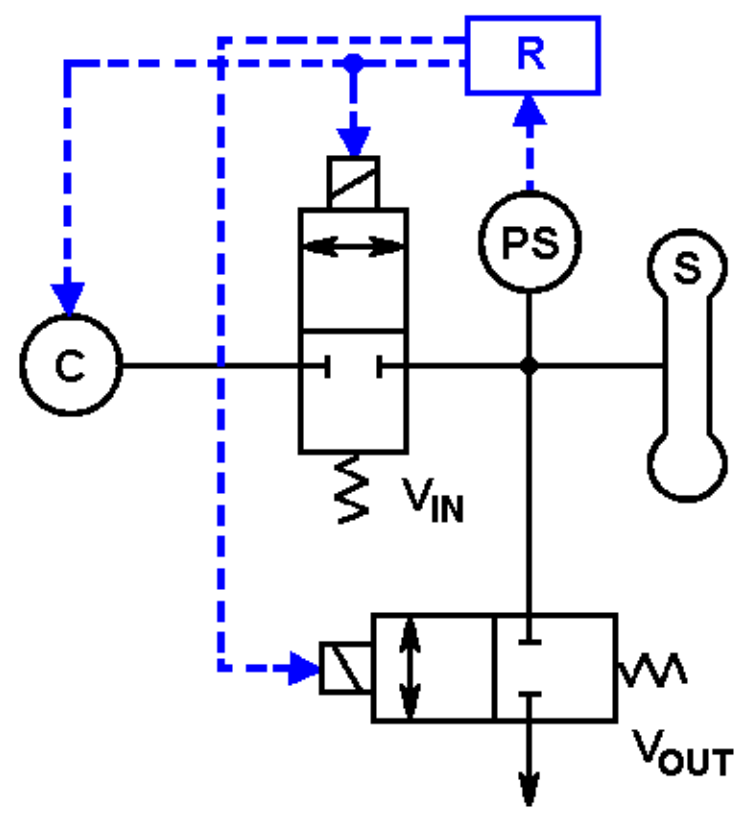

Fig. 4. Pneumatic circuit with own compressor and input valve

The last configuration is shown in Fig. 5. A central compressor $\mathrm{C}$ is used as a source of compressed air together with an air reservoir AR. The pressure in this air tank is measured by a PR sensor and is independently controlled by an auxiliary control system R1. The main control circuit then controls the inlet valve Vin if necessary to increase the pressure in the seat element or the valve Vout if necessary to decrease the pressure in the seat. 


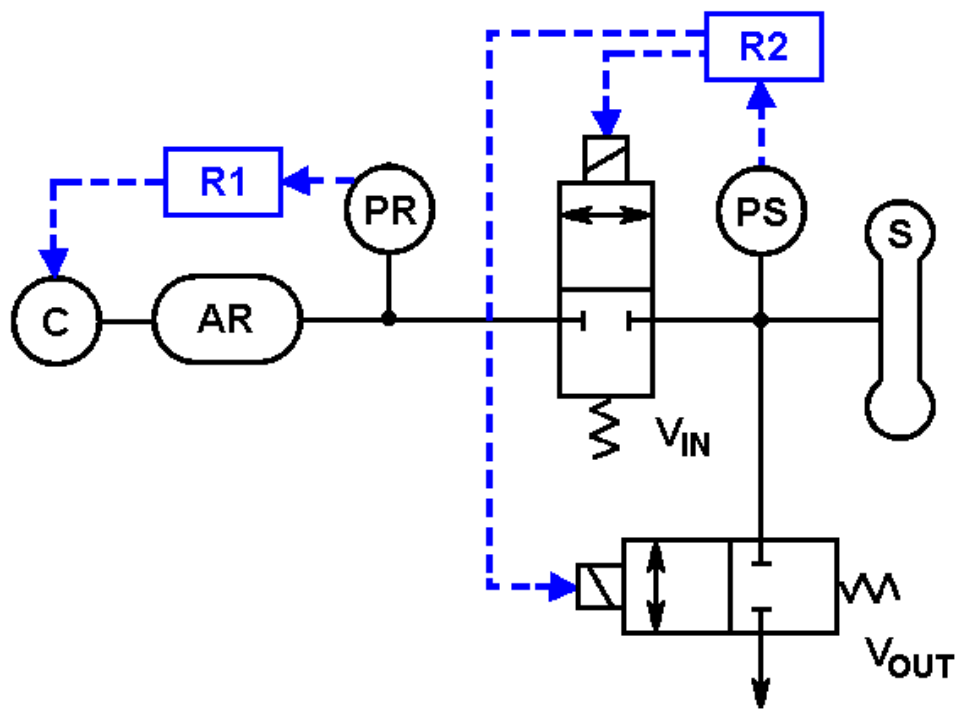

Fig. 5. Pneumatic circuit with independent compressor, air reservoir and auxiliary control circuit

\section{Pneumatic valve configuration variants}

Figure 6 shows the overall pneumatic circuit with all components used for the laboratory version of the seat. Compressor $\mathrm{C}$ is connected to the analog output of the control unit and can be used either as a two-state element, ie with states off - on, or its rotation speed can be continuously controlled by PWM. There is a non-return valve at its outlet. A two-state valve Vin and a proportional valve Vain are connected in parallel at the air supply to the pneumatic element S. A pair of two-state and proportional valves Vout and Vaout are similarly connected in parallel in the discharge pipe. Manually adjustable throttle valves are added in both of these paths. The pressure in element $\mathrm{S}$ is measured by a pressure sensor PS. Exhaust air from the pneumatic element can alternatively be realized via the discharge valve Vout1.

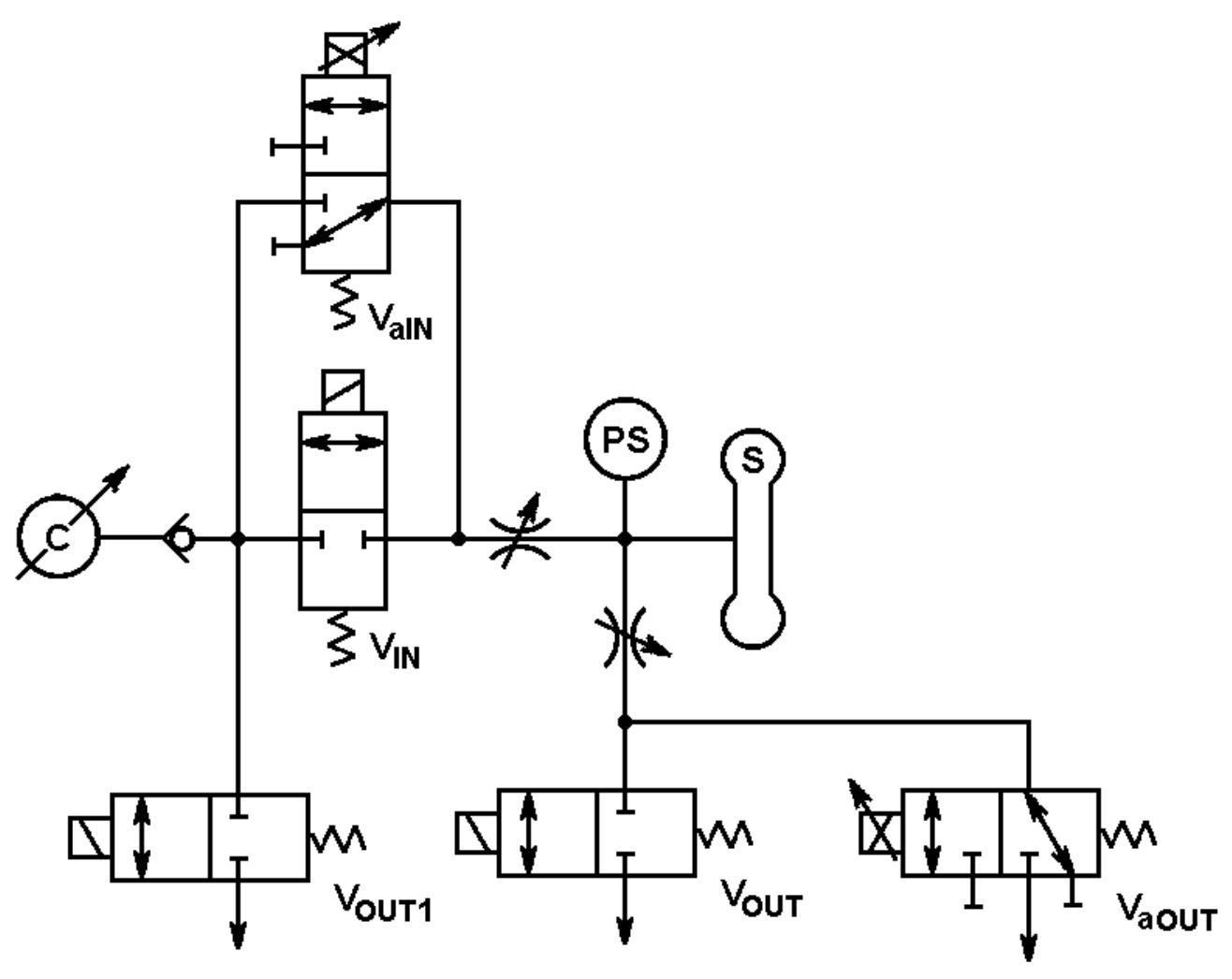

Fig. 6. Pneumatic circuit with all the components 
The controls in this pneumatic circuit can all be used simultaneously, reducing the time required to inflate and deflate the element by opening parallel paths. Or part of the members can be discarded and the pneumatic circuit is simplified. Different circuit variants are suitable for different control methods. On the standard seat, it is necessary to take into account the complexity and cost of the overall solution. Of the sixteen variants tested, the most important ones are selected in Fig.7. In variant A) two two-state valves are used and it is one of the simplest variants. For measurement purposes, throttle valves with the possibility of manual flow adjustment are located on version B). These two options are suitable for three-position seat pressure control. In variant C) a pair of analog valves is used. This variant allows continuous adjustment of the valve flow and is thus suitable for finer control using a PI controller. Variant D) is then the most economical variant suitable for three-position control or purely manual control. The inlet valve is removed and is only replaced by switching the compressor with a non-return valve. Analog proportional valves are the most expensive components used. Therefore, variants E) and F) have been proposed, where it is also a proportional control, but using only one analog valve.

In variant E), PWM compressor speed control is used as a continuous action variable on the supply line. In variant F) one of the analog valves is replaced by a cheaper discrete valve. To switch on the air supply to the seat, it is necessary to switch on the compressor $\mathrm{C}$, open the control valve $\mathrm{Va}$ and close the outlet valve Vout1. To release the air to the atmosphere, switch off compressor $\mathrm{C}$ and open control valve $\mathrm{Va}$ and outlet valve Vout1.

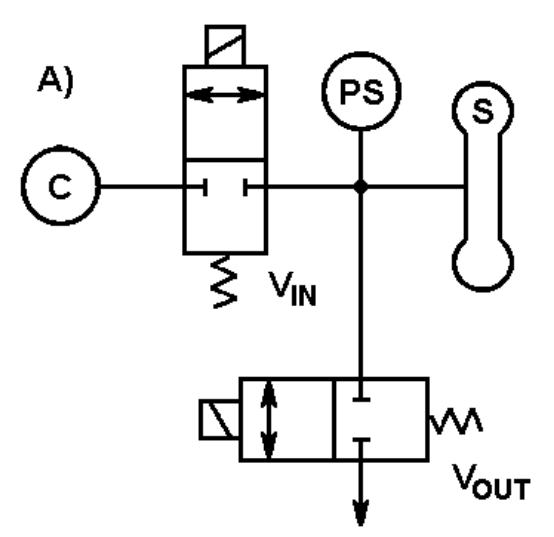

B)
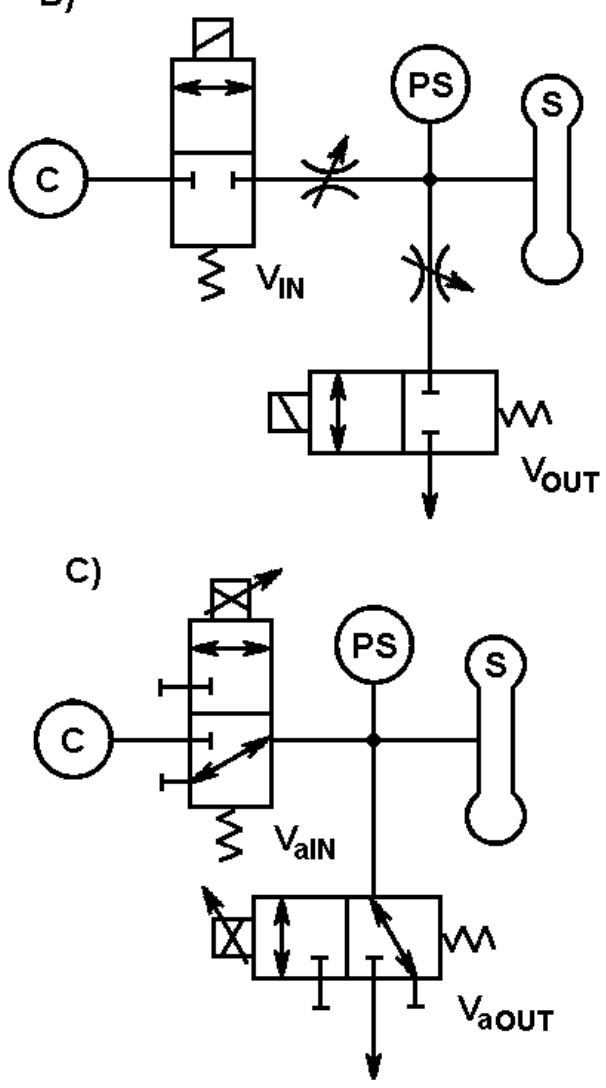

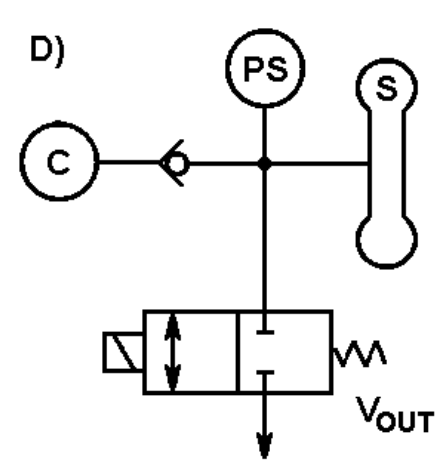

E)
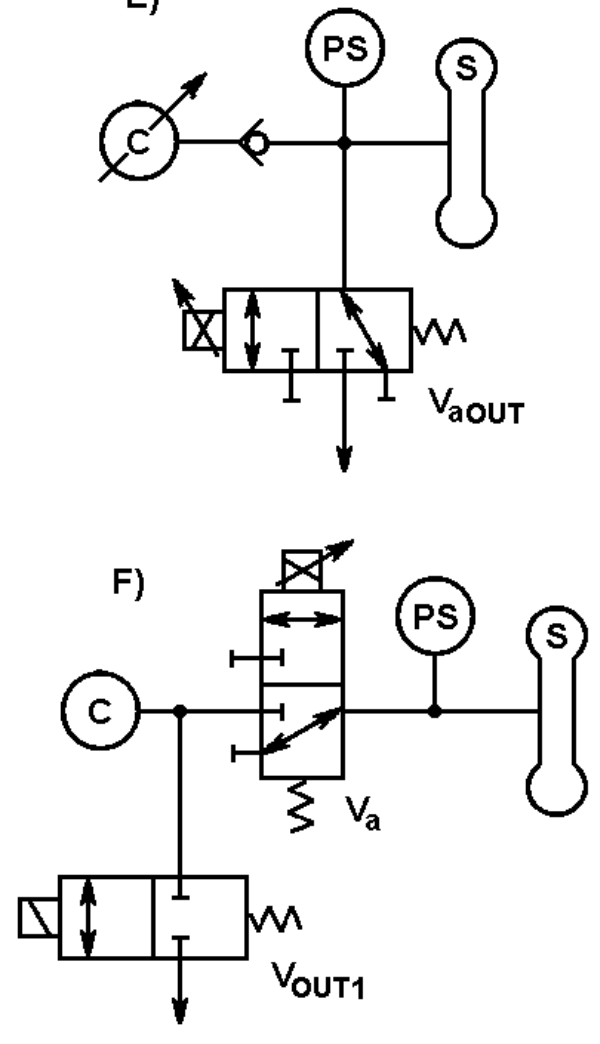

Fig. 7. Pneumatic circuits with reduced components 


\section{Control unit for the seat}

The control unit for laboratory use was designed with an Arduino microprocessor development board, Fig. 8.

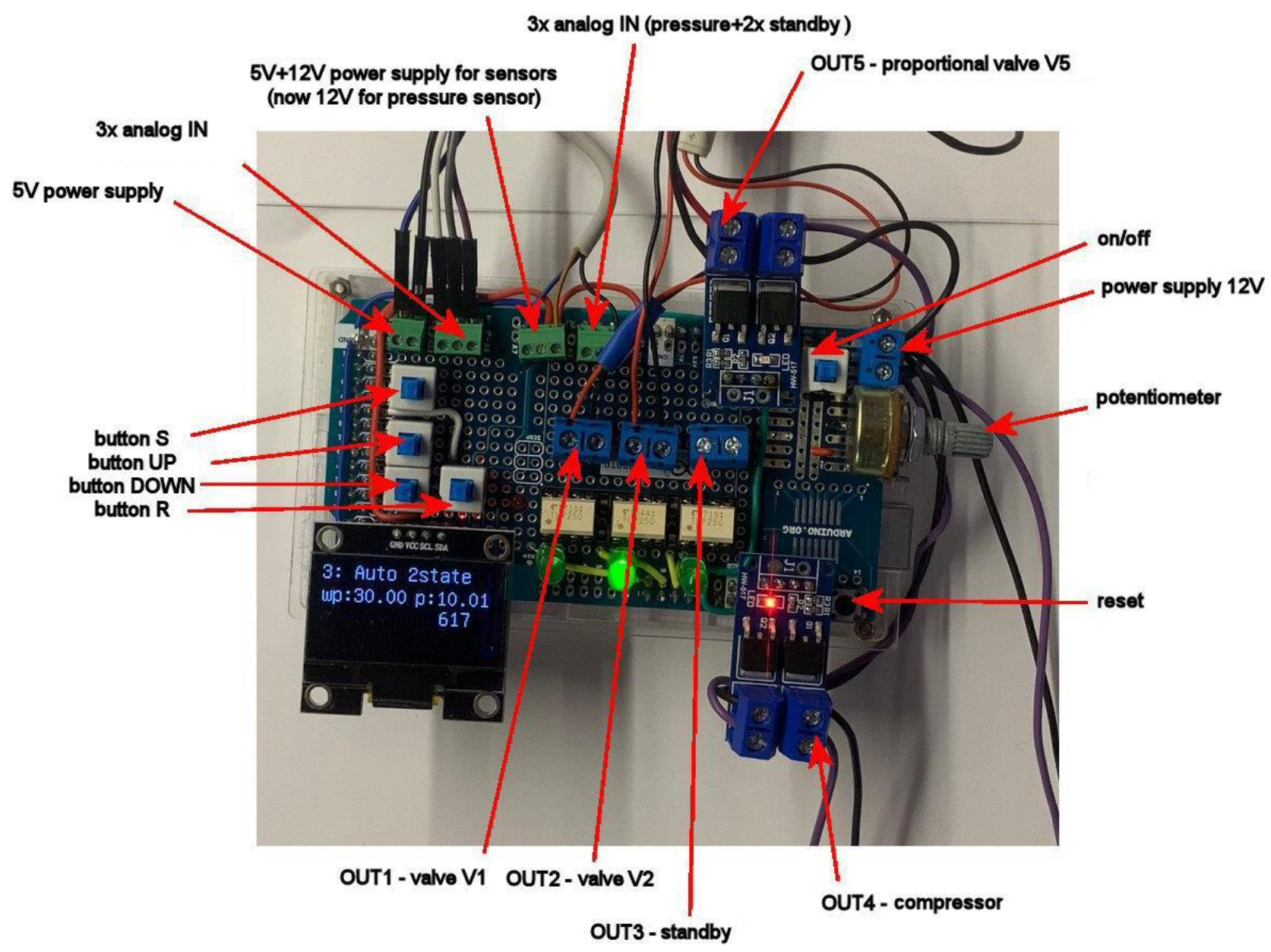

Fig. 8. Control Unit for the seat

The control unit is designed to be able to control all the components described above in chapters 2 and 3 , ie three digital valves, two analog valves, a compressor and two pressure sensors can be connected to it. Optical separation and amplifiers are designed for both discrete and analog actuators.

The control unit also contains controls for setting control modes and parameters such as pressure desired value. These elements are the buttons and the potentiometer. The individual modes and the required parameters are shown on the OLED display. Measured data can be sent online via a serial line for further processing on a PC. The block diagram of the control unit is shown in Fig.9.

There are several regimes to test various functions and control algorithms on the board. Regimes of the control unit are:

- Hand control of all actuators (valves and compressor) and reading of all sensors (pressure sensors, buttons, potentiometer)

- Hand control of pressure inside the pneumatic element

- Automatic control of pressure using three-state control algorithm, Fig.10

- Automatic control of pressure using PI control algorithm, Fig.11 


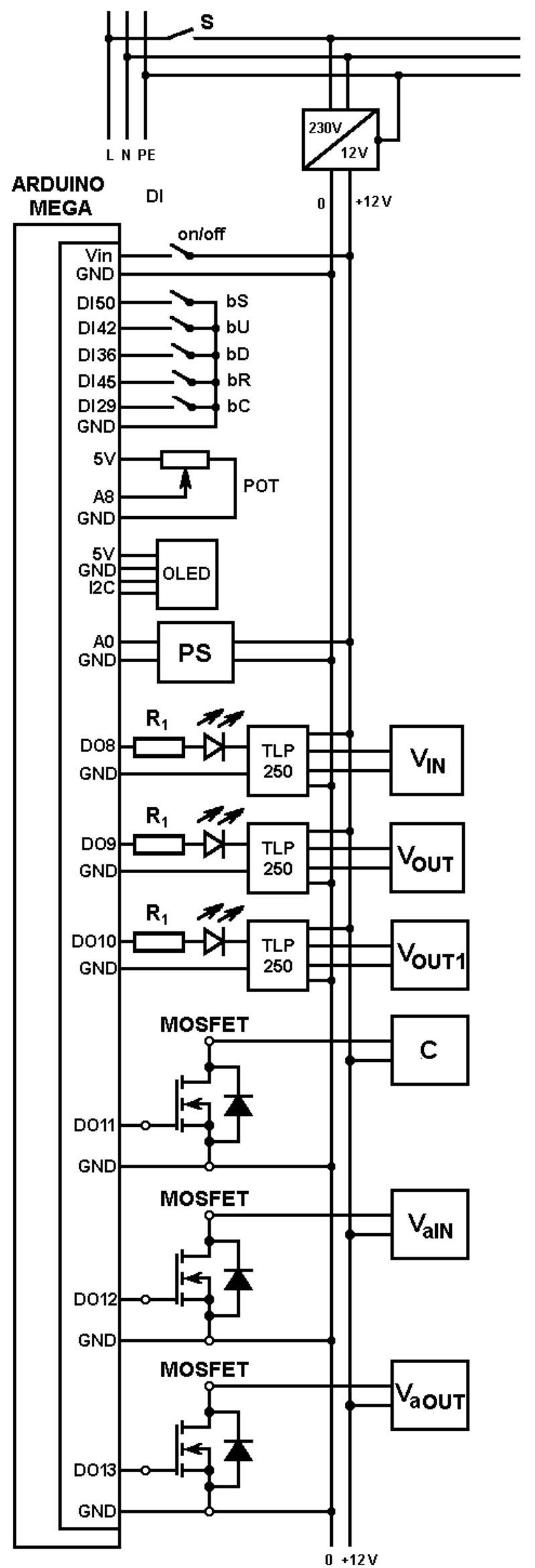

Fig. 9. Scheme of control unit 


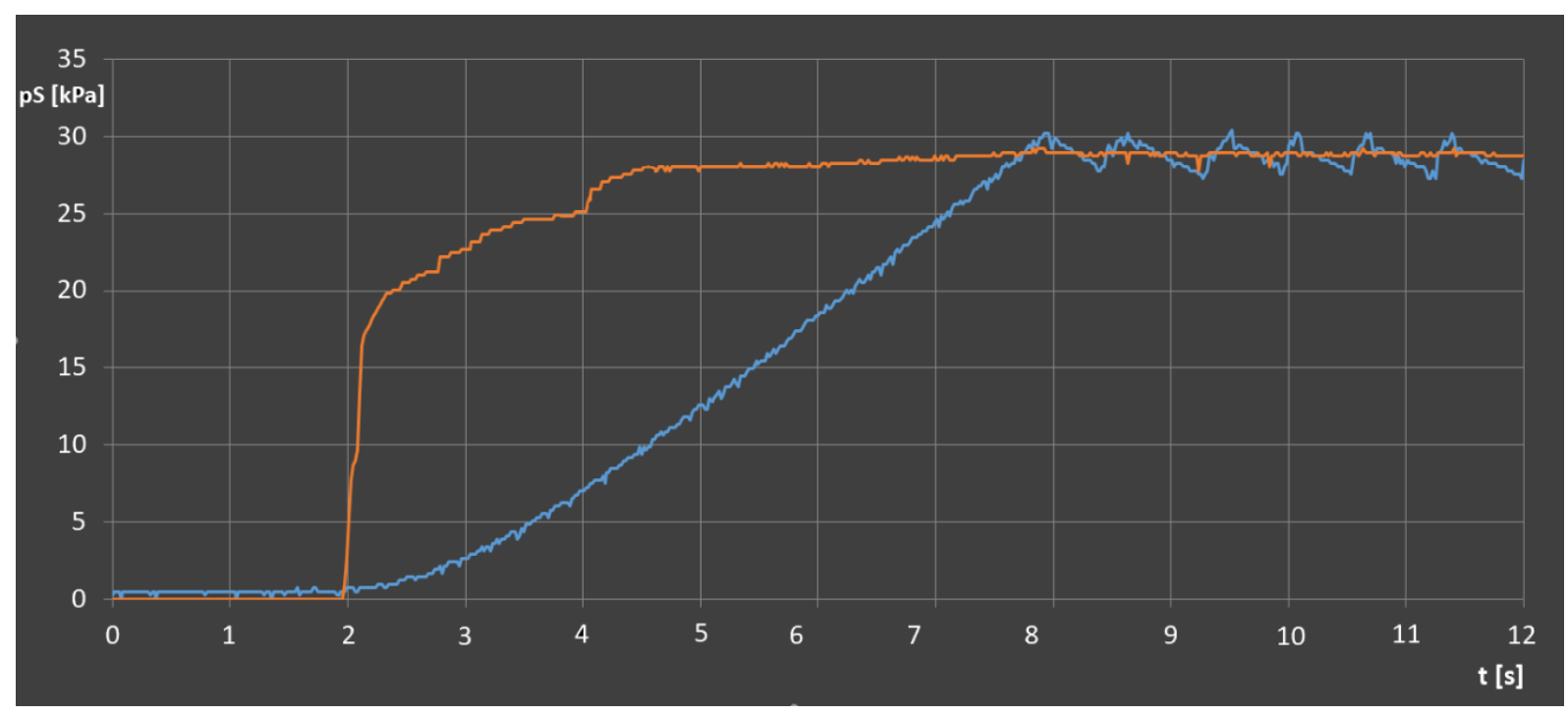

Fig. 10. Three state control

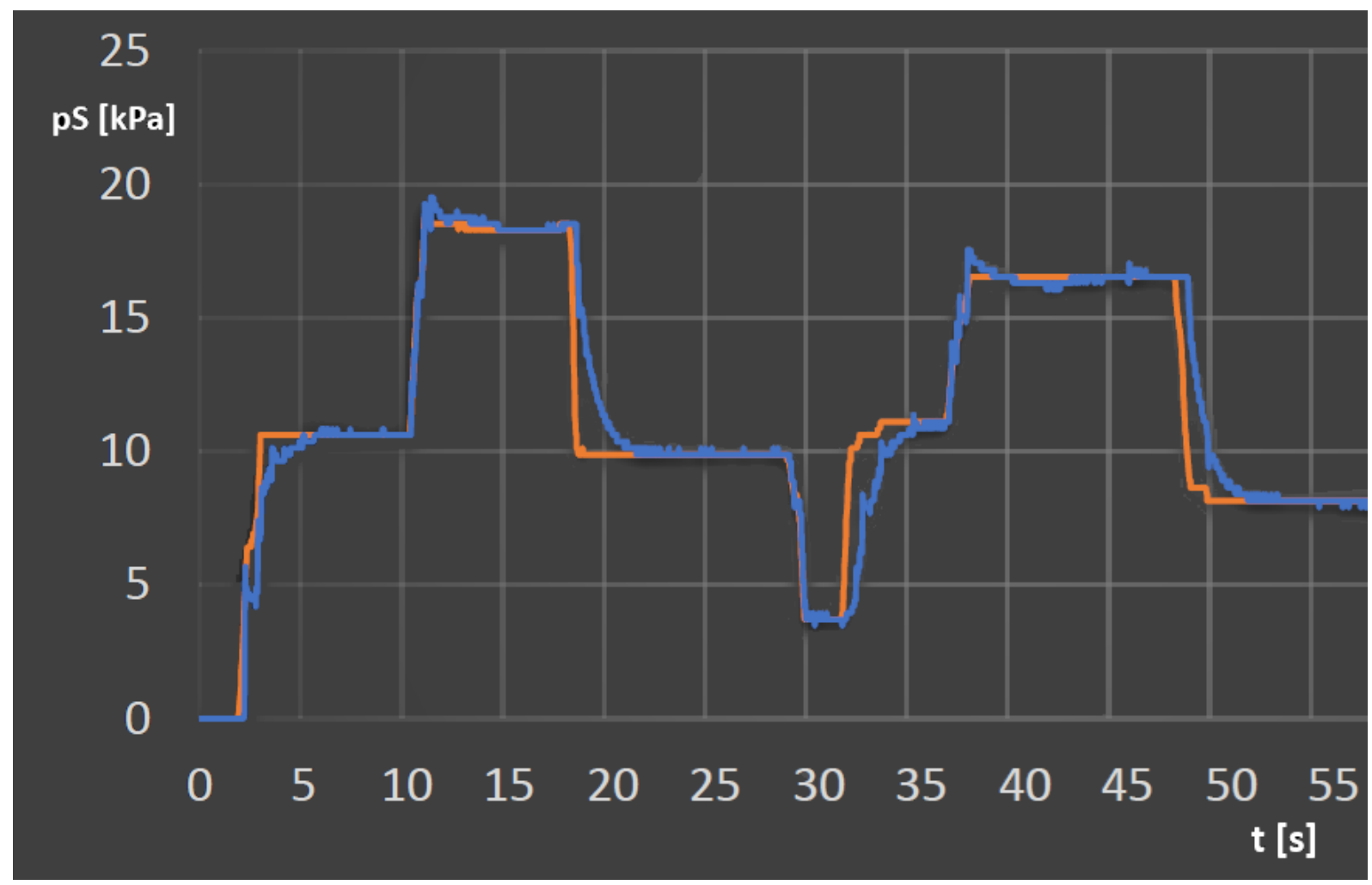

Fig. 11. PI control algorithm

There are examples of control algorithms in Fig. 10 and Fig 11. The desired value is displayed in orange and is entered using a potentiometer. The pressure course in the seat is shown in blue.

\section{Conclusion}

This article describes the development and variants of the pneumatic circuit and its control unit for a seat with adjustable seat pressure. The control unit has been designed for laboratory purposes to be able to operate in many test modes and in many pneumatic circuit configurations. The unit was implemented in a test seat and has been used for laboratory measurements. Next step in development of control unit will be transfer of presented solution from laboratory scale to industrial standard in cooperation with producer of electronic devices. Also final solution of pneumatic circuit will be selected considering the simplicity of constructional arrangement. Implemented working modes of the seat with variable stiffness must be designed with regard to estimated consumption of compressed air and capability of compressor. 


\section{Acknowledgments}

This work was supported by project „European Smarter Seats for Global Innovation in the Automotive Sector“ (ESSGIAS, no. LTE 120004). The project is co-funded by Czech Ministry of Education, Youth and Sports within the INTER-EUREKA (LTE) INTER-EXCELENCE program, supported by EURIPIDES ${ }^{2}$ and monitored by AENEAS.

\section{References}

[1] Cirkl, D., Modelling of damping force of dynamically loaded specimen of polyurethane foam in dependence on its density. Shock and Vibration 17 (2010), ISSN: 1070-9622, 373-381

[2] Votrubec, R. (2011). Control of Active Sanitary Coach, Annals of DAAAM for 2011 \& Proceedings of the 22nd International DAAAM Symposium, 23-26th November 2011, Vienna, Austria, Volume 22, No. 1, ISSN 1726-9679, ISBN 978-3-901509-83-4, Katalinic, B. (Ed.), pp. 0617-0618, Published by DAAAM International Vienna, Vienna.

[3] Saravanja, D. \& Grbesic, M. (2019). Application of Vibration Analysis in Journal Bearing Problems Diagnostics, Proceedings of the 30th DAAAM International Symposium, pp.0100-0106, B. Katalinic (Ed.), Published by DAAAM International, ISBN 978-3-902734-22-8, ISSN 1726-9679, Vienna,Austria, DOI: 10.2507/30th.daaam.proceedings.013

[4] Cekic, A; Muhamedagic, K.; Cohodar, M.; Begic-Hajdarevic,D. \& Biogradlija, S. (2019). Experimental Investigation of Effect of Overhang Tool Length on Tool Vibration and Surface Roughness, Proceedings of the 30th DAAAM International Symposium, pp.0184-0191, B. Katalinic (Ed.), Published by DAAAM International, ISBN 978-3-902734-22-8, ISSN 1726-9679, Vienna, Austria, DOI: 10.2507/30th.daaam.proceedings.024

[5] Wrzochal, M.; Adamczak, S.; Lomza, H. \& Luszczak,R. (2018). Testing the Susceptibility of Rolling Bearing Vibration Measurement Systems, Proceedings of the 29th DAAAM International Symposium, pp.0860-0865, B. Katalinic (Ed.), Published by DAAAM International, ISBN 978-3-902734-20-4, ISSN 1726-9679, Vienna, Austria DOI: $10.2507 / 29$ th.daaam.proceedings. 124

[6] Herman, A.; Vaclav Stourac, F.; Kyncl, J. \& Beranek, L. (2018). New Design of Polyurethane Foam Moulds for Vibrational Casted Refractory Materials, Proceedings of the 29th DAAAM International Symposium, pp.12311238, B. Katalinic (Ed.), Published by DAAAM International, ISBN 978-3-902734-20-4, ISSN 1726-9679, Vienna, Austria DOI: 10.2507/29th.daaam.proceedings.178

[7] Kharuzin, S.; Ivanov, A. \& Shmakov, O. (2017). Autonomous Control System for a Vehicle with Actively Articulated Frame, Proceedings of the 28th DAAAM International Symposium, pp.0759-0766, B. Katalinic (Ed.), Published by DAAAM International, ISBN 978-3-902734-11-2, ISSN 1726-9679, Vienna, Austria DOI: 10.2507/28th.daaam.proceedings. 107

[8] Votrubec, R. (2020). Communication Layer between Control Units within the Internet of Things, Proceedings of the 31st DAAAM International Symposium, pp.0072-0079, B. Katalinic (Ed.), Published by DAAAM International, ISBN 978-3-902734-29-7, ISSN 1726-9679, Vienna, Austria DOI: 10.2507/31st.daaam.proceedings.010

[9] Votrubec, R. \& Buchta, J. (2019). Air Flow Control of Centrifugal Fans for Personal Protection Equipment, Proceedings of the 30th DAAAM International Symposium, pp.0268-0275, B. Katalinic (Ed.), Published by DAAAM International, ISBN 978-3-902734-22-8, ISSN 1726-9679, Vienna, Austria DOI: 10.2507/30th.daaam.proceedings.035 